\title{
INTRASELLAR INTERNAL CAROTID ANEURYSM COEXISTING WITH GH-SECRETING PITUITARY ADENOMA IN AN ACROMEGALIC PATIENT
}

\author{
Lauro Seda Jr', Arthur Cukiert', Kátia C. Nogueira², Martha K.P. Huayllas², Bernardo Liberman ${ }^{2}$
}

The coexistence of pituitary adenoma and cerebral aneurysm is rare, although its prevalence is higher then would be expected in general population ${ }^{1-5}$. We report on an extremely rare condition where growth hormone $(\mathrm{GH})$ -secreting adenoma coexisted with an intrasellar internal carotid artery (ICA) aneurysm.

\section{CASE}

A 58 years old female presented with headache and acromegalic phenotype. She had hypertension for 10 years and galactorrhea for 3 years. Mean plasma GH was $8.1 \mathrm{\eta g} / \mathrm{mL}$ and mean IGF-1 level was $703 \mathrm{\eta g} / \mathrm{mL}$ (Reference: $78-258 \mathrm{\eta g} / \mathrm{mL}$ by immunoradiometric assay). Results obtained during pre- and postoperative glucose tolerance tests (OGTT) and octreotide response test (100 $\mu \mathrm{g}$ administered subcutaneously every six hours) can be seen in Table 1 and 2, respectively. Prolactin baseline level was $28.6 \mathrm{\eta g} / \mathrm{mL}$ and pituitary function was otherwise intact. Magnetic resonance imaging (MRI) of the sellar region disclosed a $1.2 \mathrm{~cm}$ ICA aneurysm occupying the left hemisella and a $0.7 \mathrm{~cm}$ pituitary adenoma just bellow it (Fig 1A). Angiography disclosed left ICA aneurysm posterior to the emergency of the ophthalmic artery (Fig 1B). The patient tolerated well a balloon occlusion test and was submitted to aneurysm exclusion through ICA occlusion in the neck and transcranial clipping of the supraclinoid ICA immediately below the ophthalmic artery's exit. One month afterwards, she was submitted to complete adenoma removal through a transsphenoidal approach (Fig 2). The excluded aneurysm was easily seen occupying the entire left hemisella. Immunohistochemical examination confirmed the presence of GHsecreting adenoma. Immediate postoperative $\mathrm{GH}$ and prolactin levels were 3.7 and $5.6 \mathrm{\eta g} / \mathrm{mL}$, respectively. Four days later, IGF1 was $543 \mathrm{\eta g} / \mathrm{mL}(78-258 \mathrm{\eta g} / \mathrm{mL})$. One month after adenoma removal, GH and IGF1 levels were $5.0 \mathrm{\eta g} / \mathrm{mL}$ and $527 \mathrm{\eta g} / \mathrm{mL}$, respectively. After 3 months of follow-up, patient's GH and IGF1 levels were $4.1 \mathrm{\eta g} / \mathrm{mL}$ and $413 \mathrm{\eta g} / \mathrm{mL}$, respectively. It was not possible to perform a follow-up MRI since the clip used in surgery was not MRI-compatible.

She was then started on Sandostatin ${ }^{\circledast}$ LAR $30 \mathrm{mg} /$ month. Four months later, IGF-1 and GH levels were $107 \mathrm{\eta g} / \mathrm{mL}$ (Refer-

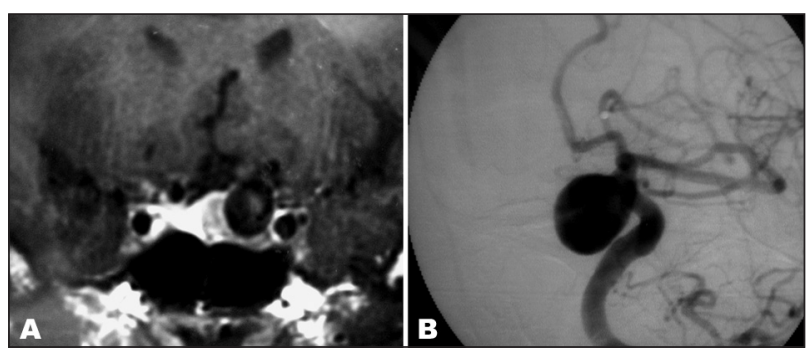

Fig 1. (A) A gadollinium-enhanced MRI showing a round flow-void mass in the left hemisella with $1.2 \mathrm{~cm}$ (arrow-head) associated to a subjadcent pituitary microadenoma (small arrow). (B) A lateralscan angiography showing a left paraclinoid ICA aneurysm directed down into the sella.

Table 1. Pre-/ postoperative oral glucose tolerance test.

\begin{tabular}{lccccc}
\hline Time (minutes) & 0 & 30 & 60 & 90 & 120 \\
\hline Glucose level $(\mathrm{mg} / \mathrm{dL})$ & $93 / 92$ & $193 / 169$ & $181 / 204$ & $150 / 174$ & $108 / 111$ \\
$\mathrm{GH}(\eta \mathrm{g} / \mathrm{mL})$ & $11.4 / 2.7$ & $6.6 / 1.1$ & $6.8 / 2.7$ & $6.8 / 2.5$ & $7.1 / 2.7$ \\
\hline
\end{tabular}

Table 2. Octreotide acute response test (100 $\mu \mathrm{gsc} 6 / 6 \mathrm{~h})$.

\begin{tabular}{cccccccc}
\hline Time (hours) & 0 & 2 & 4 & 6 & 8 & 24 & 26 \\
\hline $\mathrm{GH}(\eta \mathrm{g} / \mathrm{mL})$ & 5.5 & 0.44 & 0.52 & 0.63 & 0.71 & 0.37 & 0.22 \\
\hline
\end{tabular}

\footnotetext{
ANEURISMA INTRASELAR DA CARÓTIDA INTERNA COEXISTINDO COM ADENOMA SECRETOR DE GH EM PACIENTE ACROMEGÁLICO

Departments of Neurosurgery' and Endocrinology², Hospital Brigadeiro and Clínica Neuroendócrina de São Paulo, São Paulo SP, Brazil.

Received 14 May 2007, received in final form 18 October 2007. Accepted 1 December 2007.
}

Dr. Arthur Cukiert - Rua Dr. Alceu de Campos Rodrigues 247 / 121 - 04544-000 São Paulo SP - Brasil. E-mail: acukiert@uol.com.br 


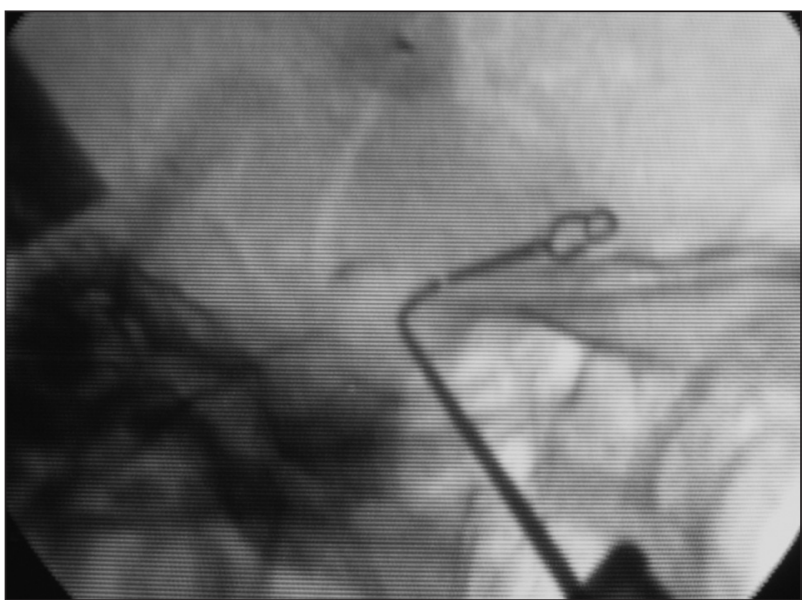

Fig 2. An intraoperative plain film showing a lateral view of the sellar region depicting the relationship between the previously clipped ICA and the curette during the transsphenoidal removal of adenoma.

ence: $81-225 \eta \mathrm{g} / \mathrm{mL}$ ) and $0.9 \eta \mathrm{g} / \mathrm{mL}$, respectively. By this time, patient underwent radiosurgery. After two years of follow-up, the patient remained in remussion and receiving Sandostatin LAR.

This case report was agreed by the local ethic committee.

\section{DISCUSSION}

The prevalence of sellar-region's aneurysm among others is $1-2 \%^{2}$. The prevalence of the coexistence of pituitary adenoma and cerebral aneurysm is higher then that with other benign brain tumors in the general population ${ }^{5}$. Approximately $50 \%$ of these patients have acromegaly ${ }^{1,3,5-8}$, suggesting that high GH and IGF-1 levels or their biological effects might be implicated in the aneurysm's genesis. High IGF-1 induces artery dilation ${ }^{8}$, atherosclerotic and degenerative changes of the artery wall ${ }^{8,9}$, tumor invasion and tumor-directed neovessels ${ }^{9}$. Hypertension and diabetes are very likely to be involved in the process ${ }^{5}$. Patients with intrasellar (not intracranial) aneurysms and pituitary adenomas are extremely rare.

Mostly, the diagnosis of such aneurysms is incidental, and occurs when performing the preoperative investigation for adenomas ${ }^{7}$. However, different clinical presentations may occur, such as fatal epistaxis ${ }^{10}$ or pituitary apoplexy ${ }^{11}$, as a result of aneurismal bleeding into the adenoma. Misdiagnosis of this condition may have hazardous hemorrhagic consequences.

These two conditions must be treated. Although simultaneous microsurgical treatment of the aneurysm and the adenoma through a pterional or a supraorbital keyhole approach has been advocated in different reports ${ }^{6,12,13}$, approaching the vascular lesion first is usually the best choice. In our case, we performed an ICA entrapment by endovascular occlusion in the neck and transcranial clipping of ICA just bellow the ophthalmic artery's emergence. This treatment was possible because the patient tolerated well a previous balloon occlusion test. One month later, the adenoma was completely removed through a transsphenoidal route. Nevertheless, the patient did not achieved endocrinological remission and needed adjuvant therapy with Octreotide and radiosurgery. Clinical and endocrinological control were then obtained.

Although the results obtained while treating this patient were good, a minimally invasive therapeutic option would also be available for such patients: the vascular lesion could be treated by endovascular trapping of the internal carotid artery and the $\mathrm{GH}$-secreting tumor could have been treated primarily with somatostatin analogs or transsphenoidal surgery. Primary clinical treatment with somatostatin should be considered especially in patients with known cavernous sinus invasion by the tumor and no mass effect directed to the optic apparatus ${ }^{14-15}$.

We believe that the treatment of this dual-pathology should be carried out in two steps: vascular pathology should be treated first to avoid potential future catastrophic hemorrhage and the pituitary pathology afterwards.

\section{REFERENCES}

1. Jakubowski J, Kendall B. Coincidental aneurysms with tumors of pituitary origin. J Neurol Neurosurg Psychiatry 1978;41:972-979.

2. Acqui M, Ferrante L, Fraioli B. Association between intracranial aneurysms and pituitary adenomas: etiopathogenic hypotheses. Neurochirurgia 1987;30:177-181.

3. Pant B, Arita K, Kurisu K. Incidence of intracranial aneurysms associated with pituitary adenoma. Neurosurg Rev 1997;20:13-17.

4. Heshmati HM, Fatourechi V, Dagam SA, Piepgras DG. Hypopituitarism caused by intrasellar aneurysms. Mayo Clin Proc 2001;76:789-793.

5. Wakai S, Fukushima T, Furihata T. Association of cerebral aneurysm with pituitary adenoma. Surg Neurol 1979;12:503-507.

6. Hori T, Muraoka K Hokama Y. A growth-hormone producing pituitary adenoma and an internal carotid artery aneurysm. Surg Neurol 1982;18: 108-111.

7. Sade B, Mohr G, Tampieri D, Rizzo A. Intrasellar aneurysm and a growth hormone-secreting pituitary macroadenoma. J Neurosurg 2004; 100:557-559

8. Weir B. Pituitary tumors and aneurysms case report and review of the literature. Neurosurgery 1992;30:585-591.

9. Mangiardi JR, Aleksic SN, Lifshitz M. Coincidental pituitary adenoma and cerebral aneurysm with pathological findings. Surg Neurol 1983;19: 38-41.

10. Imamura J, Okuzono T, Okuzono Y. Fatal epistaxis caused by rupture of an intratumoral aneurysm enclosed by a large prolactinoma: case report. Neurol Med Chir 1998;38:654-656.

11. Suzuki H, Muramatsu M, Murao K. Pituitary apoplexy caused by ruptured internal carotid aneurysm. Stroke 2001;32:567-569.

12. Fujiwara S, Fujii K, Nishio S. Diagnosis and treatment of pituitary adenoma with adjacent carotid artery aneurysm. J Neurosurg Sci 1991;35: 41-46.

13. Revuelta R, Arraiada-Mendicoa N, Ramirez-Alba J. Simultaneous treatment of a pituitary adenoma and an internal carotid artery aneurysm through a supraorbital keyhole approach. Minim Invasive Neurosurg 2002;45:109-111.

14. Vieira JO, Cukiert A, Liberman B. Evaluation of MRI criteria for cavernous sinus invasion in patients with pituitary adenoma: logistic regression analysis and correlation with surgical findings. Surg Neurol 2006;65:130-135.

15. Vieira JO, Cukiert A, Liberman B. MRI of cavernous sinus invasion by pituitary adenoma: diagnostic criteria and surgical findings. Arq Neuropsiquiatr 2004;62:437-443. 